\title{
Mechanical Properties of Palm Fibre Reinforced Recycled HDPE
}

\author{
B. Aldousiri, ${ }^{1}$ M. Alajmi, ${ }^{2}$ and A. Shalwan ${ }^{2,3}$ \\ ${ }^{1}$ Department of Power \& Desalination Plants, Ministry of Electricity, Kuwait City, Kuwait \\ ${ }^{2}$ Mechanical Production Engineering Department, College of Technological Studies, PAAET, Kuwait City, Kuwait \\ ${ }^{3}$ Centre of Excellence in Engineered Fiber Composites (CEEFC), Faculty of Engineering and Surveying, \\ University of Southern Queensland, Toowoomba, QLD 4350, Australia
}

Correspondence should be addressed to A. Shalwan; abdullah.alajmi@usq.edu.au

Received 16 April 2013; Accepted 27 April 2013

Academic Editor: Belal F. Yousif

Copyright (c) 2013 B. Aldousiri et al. This is an open access article distributed under the Creative Commons Attribution License, which permits unrestricted use, distribution, and reproduction in any medium, provided the original work is properly cited.

Recently, recycled thermoplastic polymers become an alternative resource for manufacturing industrial products. However, they have low mechanical properties compared to the thermosets. In this paper, an attempt has been made to enhance the mechanical properties of recycled high density polyethylene (HDPE) with chopped strand mat (CSM) glass fibres as a synthetic reinforcement and with short oil palm fibres as a biodegradable (natural) reinforcement. The effects of volume fraction of both synthetic and natural fibres on tensile, compression, hardness, and flexural properties of the HDPE were investigated. The failure mechanism of the composite was studied with the aid of optical microscopy. Tensile properties of the HDPE composites are greatly affected by the weight fraction of both the synthetic and the natural fibres. The higher strength of the composites was exhibited when at higher weight fraction of both natural and syntactic fibres which was about $50 \mathrm{MPa}$. Date palm fibre showed good interfacial adhesion to the HDPE despite the untreated condition used. On the other hand, treatment of the fibres is recommended for higher tensile performance of the composites.

\section{Introduction}

Polymers have emerged as the material used in different applications. This is due to their unique and attractive properties compared to the metal materials; that is, they own excellent impact and abrasion resistance, high strength-toweight ratio, and high durability which fulfil the requirement for many designs in manufacturing components $[1,2]$. However, there are several issues that limit the usage of such materials due to their need for synthetic reinforcements $[3,4]$. Nowadays, there are regulations and carbon tax implemented in several developed countries which limits the usage of fossil products $[5,6]$. This motivates the researchers and the mechanical designers to find alternative to the synthetic products. Natural fibres could be one of the most useful alternative reinforcements to the synthetic fibres such as glass, carbon, and Kevlar [7].

In the current decade, natural fibres such as coconut [8], oil palm [9], bamboo [7], and sugarcane fibres [10] are attractive candidates and the usage of natural fibres to reinforce polymer has increased dramatically. However, there are still several potential fibres that have not been discovered yet. Date palm fibres are available in the Middle East in huge amounts [11, 12], and there is no much understanding of the mechanical properties of such fibre. This motivates the current work to be on the influence of the date palm fibre on the mechanical properties of the thermoplastic materials. Beside the aforementioned, thermoplastic materials have numerous applications in different industrial and academic sectors. Thermoplastics have the advantage of the recyclability compared to the thermoset polymers $[13,14]$. Highdensity polyethylene is a potential recyclable matrix which showed excellent recyclability in several reported works [15, $16]$.

In the light of the above, the combination of environmental friendly characteristics of natural fibres and recycle HDPE polymer in developing a biorecyclable composite will be very attractive research. In the current study, the HPDE 
is reinforced with date palm fibres and/or chopped glass fibres. Tensile, compressive, and hardness properties of the composites were evaluated at different weight fractions of fibres and orientations.

\section{Materials and Experiments}

Raw mesh (natural mat) surrounding the date palm tree stems ws collected from a date palm farm in Kuwait. The fibres were separated from the meshes manually and washed with a tap water ( $2 \%$ detergent solution) to remove the contaminants and adhering dirt and dust. The extracted fibres were air-dried for $48 \mathrm{~h}$ at room temperature. At this stage, optical microscopy was used to check the fibre and select the desired ones. Also, the fibre diameter of $0.7 \pm$ $0.05 \mathrm{~mm}$ was selected in order to availability, and maturity of fibres at this diameter. In determining the fibre diameter, three measurements were taken at different cross-sections in each fibre and average diameter was calculated. Then the fibres were cut to the desired length and preserved in polyethylene bags. In this study, the extracted fibres are treated with sodium hydroxide $(\mathrm{NaOH})$ for $24 \mathrm{~h}$ at room temperature. Then, the fibres are rinsed with fresh water and dried at room temperature for $24 \mathrm{~h}$ before preservation in right polyethylene bag to reduce the moisture absorption until they are used.

In the current study, several composites were prepared using hot press techniques. High density polyethylene reinforced with different weight fractions of chopped strand mar glass fibres and/or date palm fibres is prepared. Six types of composite blocks that have to be prepared are as follows:

(1) pure HDPE,

(2) HDPE with $6 \%$ chopped strand mat glass fibre (CSM),

(3) HDPE with 6\% palm fibre (OPF),

(4) HDPE with $6 \% \mathrm{PF}$ and $2 \%$ CSM,

(5) HDPE with $6 \% \mathrm{PF}$ and $4 \%$ CSM,

(6) HDPE with 6\% PF and 6\% CSM.

Schematic drawing shows the fibre orientation in the composites presented in Figure 1. In the preparation, unidirectional geometry is selected since it is the recommended orientation in the literature [17].

2.1. Experimental Procedure. Mechanical properties of the developed composites were studied considering the tensile, compressive, and hardness characteristics. It is well known that when the fibre was oriented in the direction of the tensile applied load, the higher tensile strength can be achieved compared to other orientations [18-20]. Therefore, in the tensile testing, the composites were oriented in a way where the fibres are parallel to the direction of the applied load. On the other hand, since there is less work on the compressive and hardness of such composites [21-23], compressive and hardness tests were performed in two directions with respect to the applied load. In the horizontal direction, the applied load is perpendicular to the fibre mats, and, for the parallel, the fibre mats are parallel to the applied load.

\section{Result and Discussion}

Tensile, compressive, and hardness results are presented in Figures 2-8 including samples of the micrographs of the fractured samples. It should be mentioned here that the tensile experiments have been conducted in one orientation with respect to the fibre ends. In this orientation, the fibres were parallel to the applied load. However, in the compression and hardness tests, the samples were tested in two fibre orientations, that is, one parallel to the applied load and another opposite.

3.1. Tensile Behaviour. Figure 2 shows a sample of the tensile behaviour of the developed composites. From the figure, it is clear that all the composites exhibit ductile behaviour which is very desirable in the components design. It is well known that glass fibres are very brittle materials and always are not recommended as reinforcement for composites under fatigue loading conditions. In the current study, it can be seen that the addition of the date palm fibre preserves the ductility of the high density polyurethane despite the glass fibre addition in the composites. The summary of the three tests of each composite is listed in Table 1 . In this table, it can be seen that the addition of either glass fibre or the date palm fibre enhances the mechanical properties of the HDPE since there is a significant increase in the tensile strength of the HDPE from $28 \mathrm{MP}$ to about $50 \mathrm{MPa}$. On the other hand, the addition of either fibre has slight effect on the modulus of elasticity (Young's modulus, E). One can see that the addition of $6 \%$ natural fibres increases the tensile strength of HDPE to $38 \mathrm{MPa}$ while synthetic glass fibre increases the tensile to $29 \mathrm{MPa}$ only. This is mainly due to the fact that glass fibre has poor interfacial adhesion with the HDPE matrix. The combination of both synthetic and natural fibres assists in increasing the tensile strength of the HDPE to the maximum value of $50 \mathrm{MPa}$.

The SEM observation in Figure 3 indicates that there is low pull out of natural fibres since a good adhesion of the fibres appears. This shows the support of the natural fibres to the matrix during the loading conditions, [7]. In other works $[1,8,24]$, the natural fibres like coconut should be treated with $\mathrm{NaOH}$ to gain good interfacial adhesion. It should be mentioned here that the natural fibres in $[1,8,24]$ were reinforced with thermosets polymers. The high strength of thermoset compared to the thermoplastics demands high interfacial adhesion to the natural fibres. This is the main reason for the chemical treatments to the natural fibres when they are reinforced with thermosets.

3.2. Compressive Behaviour. The compressive experiments conducted in two orientations as the fibres were perpendicular or parallel to the applied load (Figures 4 and 5). Figure 4 shows the stress stain diagram of the typical compressive tests for all selected composites. The figure shows a ductile behaviour for all the composites which is similar to the tensile trend as shown before. However, the tensile strength of the composites seems to be much higher than the tensile strength of the neat HDPE, that is, about $50 \%$ more than 


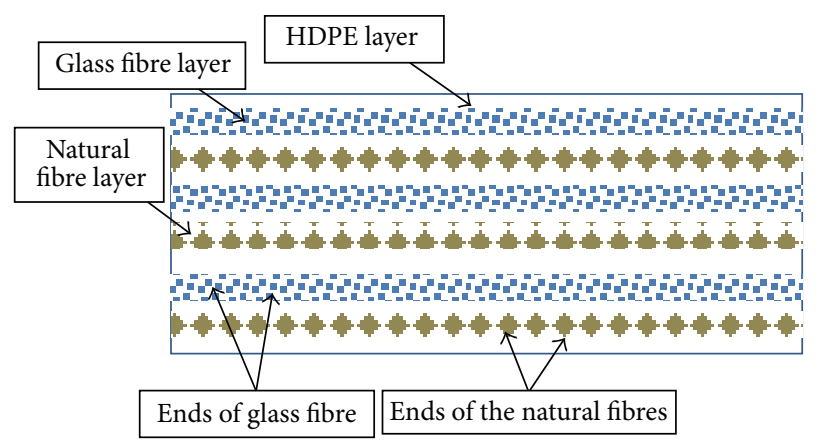

FIGURE 1: Schematic drawing shows the fibre orientation in the composites.

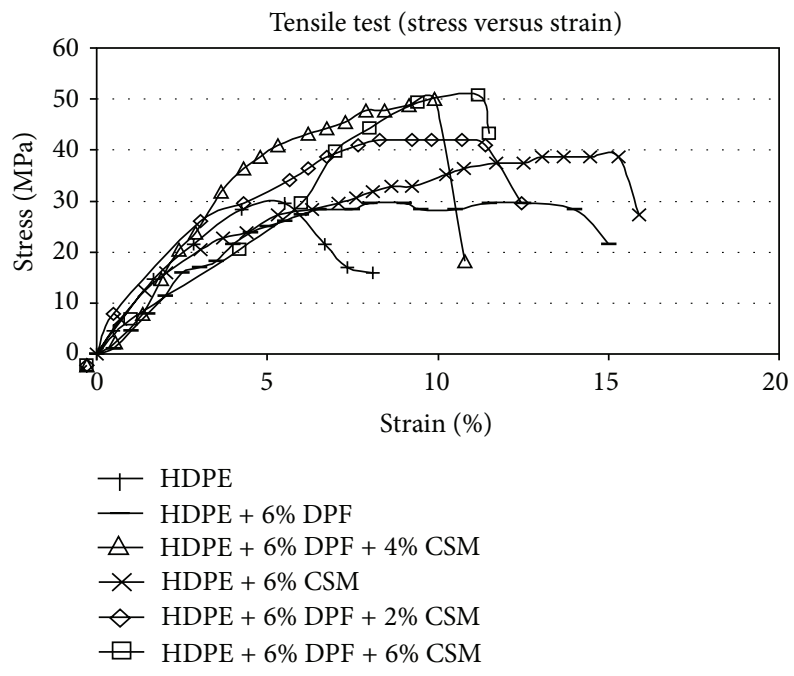

FIGURE 2: Tensile stress-strain diagram at various compositions.

the tensile strength in value. This can be observed with all the composites in horizontal direction. In this direction, the interfacial area between the fibre and the matrix is not exposed to any shear loading as in the tensile loading which in turn reduces the possibility of detachments of pull-out of fibres at high loads. The addition of either the natural fibre or the synthetic leads to higher compressive strength than the neat HDPE. Furthermore, the higher the amount of the fibres, the higher the compressive strength.

When the fibre is oriented parallel to the compressive load, the situation may change as can be seen in Figure 5 where the compressive strength reduces by about $30 \%-40 \%$ compared to another orientation of fibres. In the case of the fibre oriented parallel to the load, there is high possibility of detachments and decomposition of the composites. The compressive load transfers to shear force subjected between the fibre and the matrix along the fibre length which weakens the bonding area. Therefore, it is not recommended to use this composite in such loading condition. On the contrary, horizontal orientation is the recommended one which can bear high stress. To understand this further, a schematic drawing is developed and displayed in Figure 6. This assists in
TABLE 1: Ultimate tensile strength and Young's Modulus for various compositions.

\begin{tabular}{lcc}
\hline Type of composites & $\begin{array}{c}\text { Ultimate } \\
\text { tensile strength } \\
\sigma \text { UT }(\mathrm{MPa})\end{array}$ & $\begin{array}{c}\text { Young's } \\
\text { Modulus } \\
E(\mathrm{MPa})\end{array}$ \\
\hline HDPE & $28 \pm 5$ & 350 \\
HDPE + 6\% CSM & $29 \pm 8$ & 200 \\
HDPE + 6\% DPF & $38 \pm 3$ & 330 \\
HDPE + 6\% DPF + 2\% CSM & $40 \pm 6$ & 300 \\
HDPE + 6\% DPF + 4\% CSM & $50 \pm 7$ & 250 \\
HDPE + 6\% DPF + 6\% CSM & $50 \pm 3$ & 350 \\
\hline
\end{tabular}

understanding the two orientations of the fibre with respect to the compressive applied load since there is less possibility of damage in the interface of the fibres with the matrix when the horizontal orientation was used. Similar findings were reported when the load was in tensile condition [20,25].

3.3. Hardness Characteristics. The shore D hardness values of all the selected composites at both orientations (horizontal and vertical) are given in Figures 7 and 8 , respectively. In both orientations, there is no remarkable influence of both types of fibres on the value of the HDPE hardness. Moreover, there is no effect of the fibre orientation on the hardness for all the composites. This can be explained by the fact that the hardness was measured on the neat HDPE surfaces especially in the case of the horizontal orientations. In the case of the vertical orientation, the hardness device needle is either on the HDPE matrix or on the interface of the fibre with the HDPE since the fibres ends are very small (cf. Figure 5). There are no reported works on the hardness of the thermoplastic materials reinforced with either synthetic or natural fibres. However, there are some works on the polyester and epoxy thermoset hardness $[26,27]$. In those works, the hardness of the epoxy was very high compared to the reported ones in this work which was above 90 shore $\mathrm{D}$. This is mainly due to the fact that the thermosets materials are always harder than the thermoplastic despite the fact that HDPE is reinforced with thermoset fibres (glass). 


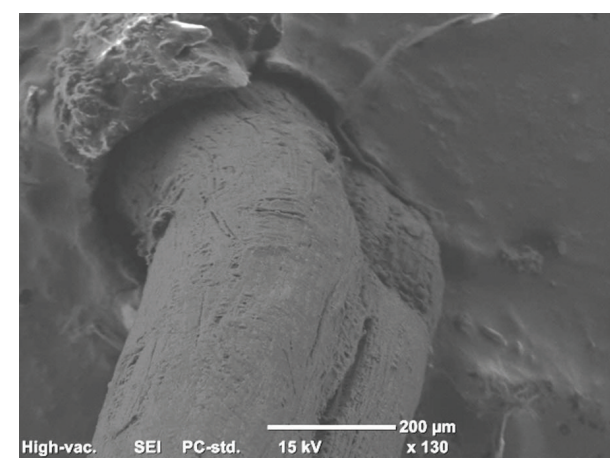

(a)

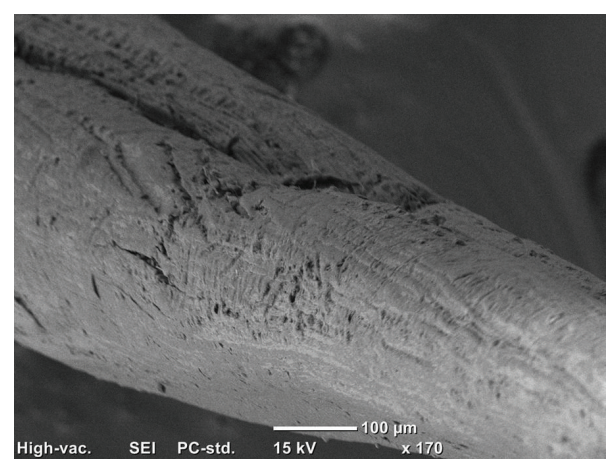

(b)

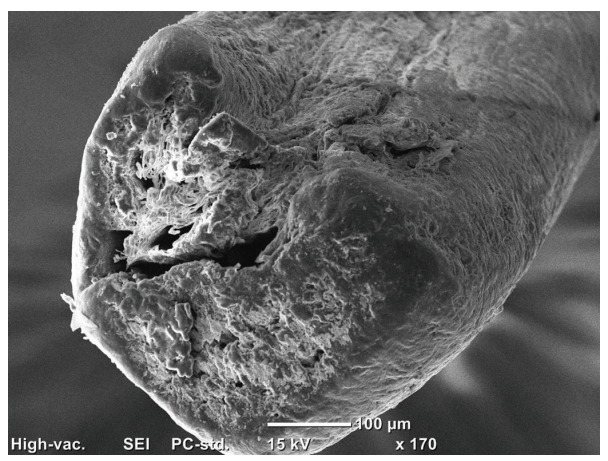

(c)

FIGURE 3: SEM micrographs of the date palm with the HDPE matrix.

Stress versus strain

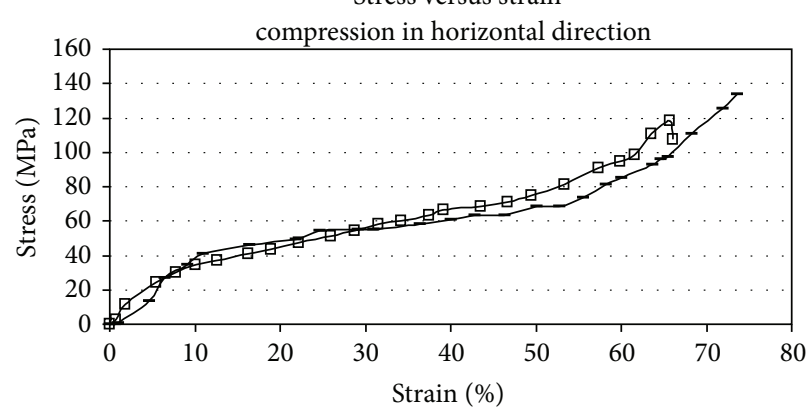

$\square$ HDPE

- $\mathrm{HDPE}+6 \% \mathrm{CSM}$

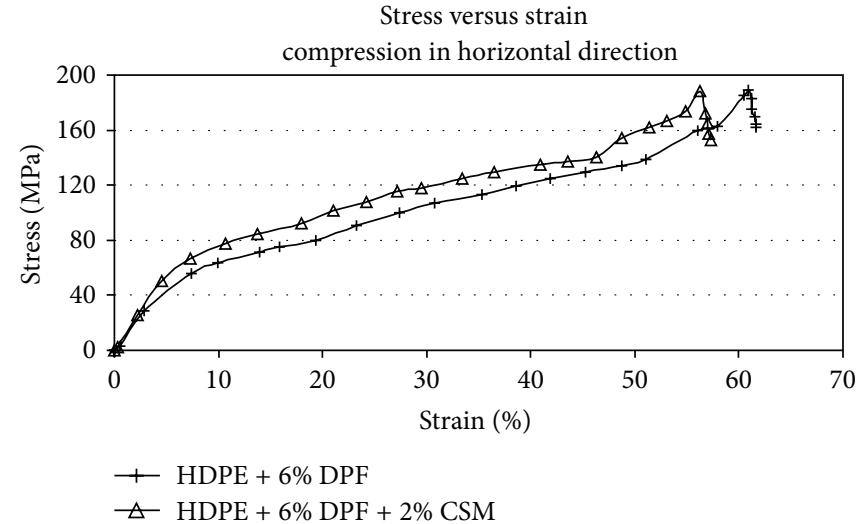

(b)

(a)

Stress versus strain

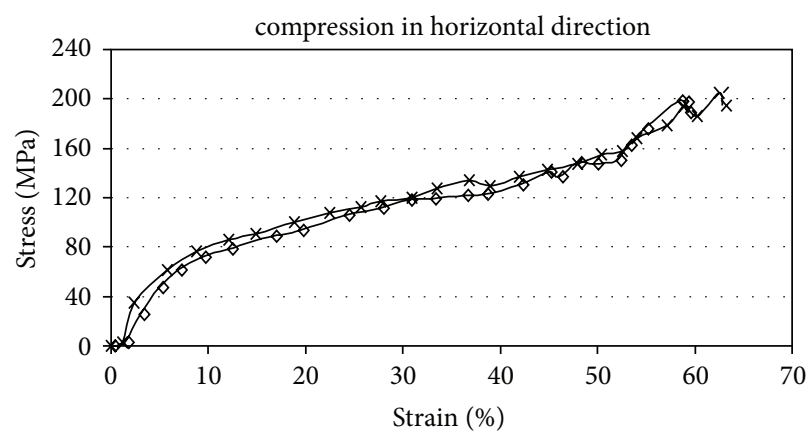

$\star \mathrm{HDPE}+6 \% \mathrm{DPF}+4 \% \mathrm{CSM}$

$\diamond \mathrm{HDPE}+6 \% \mathrm{DPF}+6 \% \mathrm{CSM}$

(c)

FIgURE 4: Compressive (horizontally) stress-strain diagram for various compositions. 


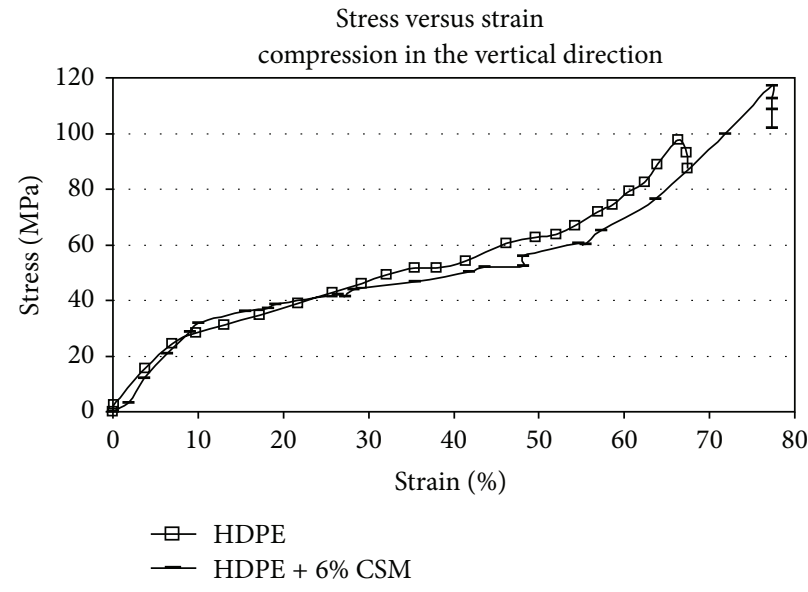

(a)

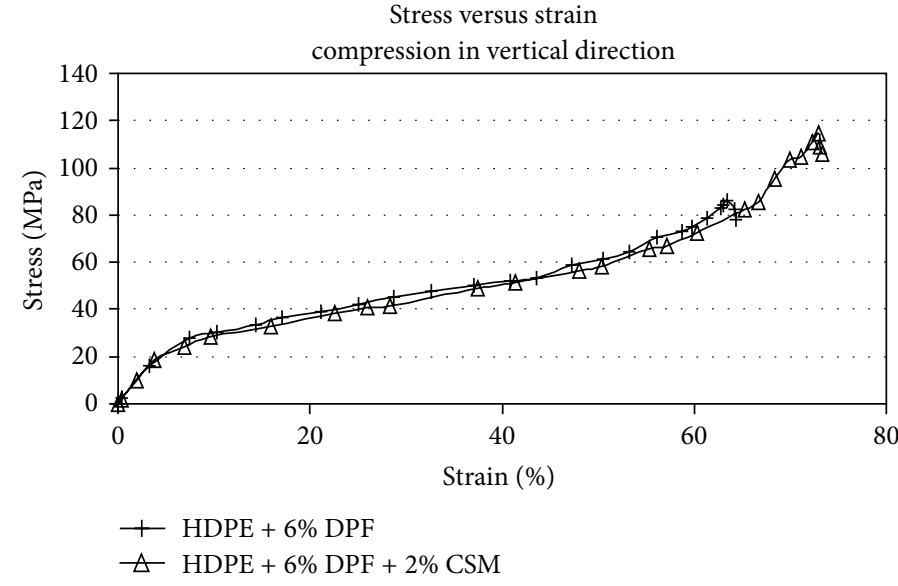

(b)

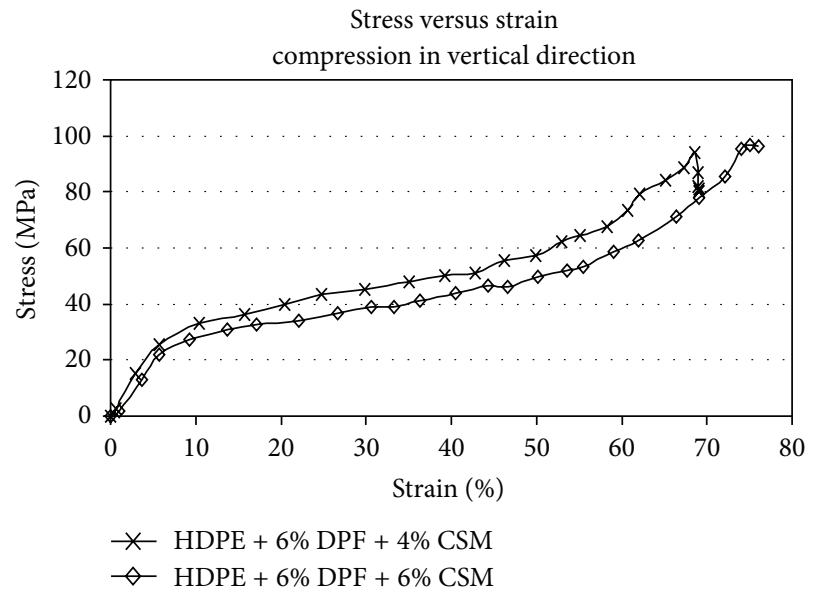

(c)

FIGURE 5: Compressive (vertically) stress-strain diagram for various compositions.

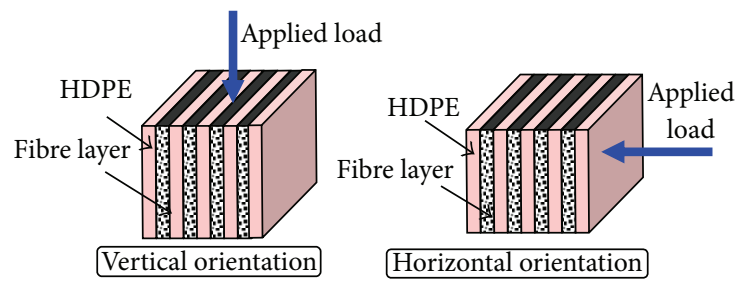

FIGURE 6: Schematic drawing showing the orientation of the fibres with respect to the applied load.

\section{Conclusions}

After conducting the experiments and discussing the findings of the current work, few points can be concluded as follows.

(1) Tensile properties of the HDPE composites are greatly affected by the weight fraction of both the synthetic and the natural fibres. The higher strength of the composites was exhibited when at higher weight fraction of both natural and syntactic fibres which was about $50 \mathrm{MPa}$.
(2) Date palm fibre showed good interfacial adhesion to the HDPE despite the untreated condition used. However, treatment of the fibres is recommended for higher tensile performance of the composites.

(3) Fibre orientation has very significant influence on compressive strength of the high density polyethylene composites. In the case of the vertical orientation, the composites suffered from detachments and delamination which resulted in low strength of the composites in this orientation. On the other hand, when the fibres were in horizontal orientation with respect to 


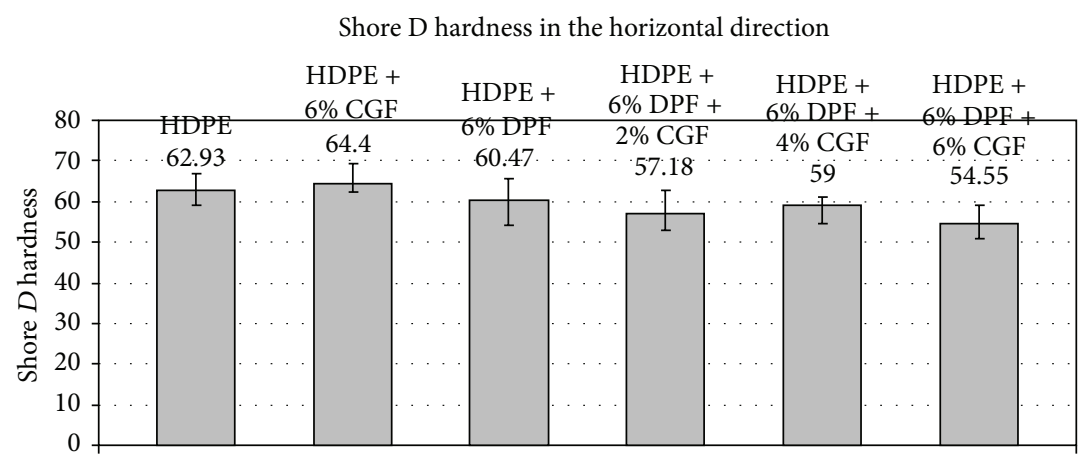

FIgURE 7: Shore D hardness values (horizontally) at various compositions.

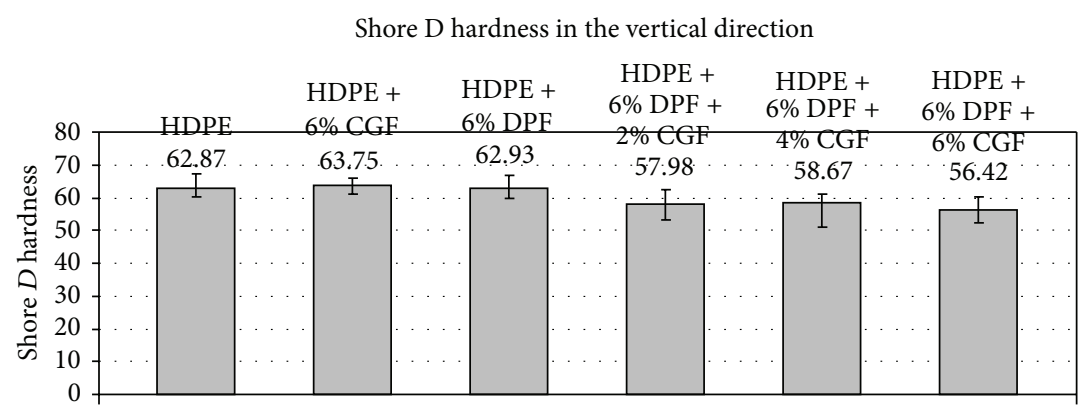

FIGURE 8: Shore D hardness values (vertically) at various compositions.

the applied load, higher resistance to the deformation was achieved.

(4) There is no remarkable influence of both the amount and the orientation of natural and synthetic fibres on the shore $\mathrm{D}$ hardness since the hardness was measured on the composites surface and there is only neat HDPE presence there.

\section{References}

[1] B. F. Yousif, "Effect of oil palm fibres volume fraction on mechanical properties of polyester composites," International Journal of Modern Physics B, vol. 24, no. 23, pp. 4459-4470, 2010.

[2] A. Shalwan and B. F. Yousif, "In state of art: mechanical and tribological behaviour of polymeric composites based on natural fibres," Materials \& Design, vol. 48, pp. 14-24, 2013.

[3] M. W. Chai, S. Bickerton, D. Bhattacharyya, and R. Das, "Influence of natural fibre reinforcements on the flammability of bio-derived composite materials," Composites B, vol. 43, no. 7, pp. 2867-2874, 2012.

[4] S. M. Hejazi, M. Sheikhzadeh, S. M. Abtahi, and A. Zadhoush, "A simple review of soil reinforcement by using natural and synthetic fibers," Construction and Building Materials, vol. 30, pp. 100-116, 2012.

[5] J. Jang, J. Lee, Y. J. Seol, Y. H. Jeong, and D. W. Cho, "Improving mechanical properties of alginate hydrogel by reinforcement with ethanol treated polycaprolactone nanofibers," Composites $B$, vol. 45, no. 1, pp. 1216-1221, 2013.

[6] K. Majeed, M. Jawaid, A. Hassan et al., "Potential materials for food packaging from nanoclay/natural fibres filled hybrid composites," Materials \& Design, vol. 46, pp. 391-410, 2013.
[7] Z. N. Azwa, B. F. Yousif, A. C. Manalo, and W. Karunasena, "A review on the degradability of polymeric composites based on natural fibres," Materials \& Design, vol. 47, pp. 424-442, 2013.

[8] A. I. S. Brígida, V. M. A. Calado, L. R. B. Gonçalves, and M. A. Z. Coelho, "Effect of chemical treatments on properties of green coconut fiber," Carbohydrate Polymers, vol. 79, no. 4, pp. 832-838, 2010

[9] S. Shinoj, R. Visvanathan, S. Panigrahi, and M. Kochubabu, "Oil palm fiber (OPF) and its composites: a review," Industrial Crops and Products, vol. 33, no. 1, pp. 7-22, 2011.

[10] S. M. Luz, A. Caldeira-Pires, and P. M. C. Ferrão, "Environmental benefits of substituting talc by sugarcane bagasse fibers as reinforcement in polypropylene composites: ecodesign and LCA as strategy for automotive components," Resources, Conservation and Recycling, vol. 54, no. 12, pp. 1135-1144, 2010.

[11] Y. El may, M. Jeguirim, S. Dorge, G. Trouvé, and R. Said, "Study on the thermal behavior of different date palm residues: characterization and devolatilization kinetics under inert and oxidative atmospheres," Energy, vol. 44, no. 1, pp. 702-709, 2012.

[12] M. A. AlMaadeed, R. Kahraman, P. N. Khanam, and S. AlMaadeed, "Characterization of untreated and treated male and female date palm leaves," Materials \& Design, vol. 43, pp. 526531, 2013.

[13] D. Glew, L. C. Stringer, A. A. Acquaye, and S. McQueen-Mason, "How do end of life scenarios influence the environmental impact of product supply chains? Comparing biomaterial and petrochemical products," Journal of Cleaner Production, vol. 30, pp. 122-131, 2012.

[14] S. Kumar, A. K. Panda, and R. K. Singh, "A review on tertiary recycling of high-density polyethylene to fuel," Resources, Conservation and Recycling, vol. 55, no. 11, pp. 893-910, 2011. 
[15] D. S. Achilias, C. Roupakias, P. Megalokonomos, A. A. Lappas, and Antonakou.V., "Chemical recycling of plastic wastes made from polyethylene (LDPE and HDPE) and polypropylene (PP)," Journal of Hazardous Materials, vol. 149, no. 3, pp. 536-542, 2007.

[16] A. Parada-Soria, H. F. Yao, B. Alvarado-Tenorio, L. SanchezCadena, and A. Romo-Uribe, "Recycled HDPE-tetrapack composites. Isothermal crystallization, light scattering and mechanical properties," MRS Proceedings, vol. 1485, 2013.

[17] S. B. Brahim and R. B. Cheikh, "Influence of fibre orientation and volume fraction on the tensile properties of unidirectional Alfa-polyester composite," Composites Science and Technology, vol. 67, no. 1, pp. 140-147, 2007.

[18] K. Liu, H. Takagi, and Z. Yang, "Dependence of tensile properties of abaca fiber fragments and its unidirectional composites on the fragment height in the fiber stem," Composites $A$, vol. 45 , pp. 14-22, 2013.

[19] F. X. Espinach, F. Julian, N. Verdaguer et al., "Analysis of tensile and flexural modulus in hemp strands/polypropylene composites," Composites B, vol. 47, pp. 339-343, 2013.

[20] A. Serrano, F. X. Espinach, F. Julian, R. del Rey, J. A. Mendez, and P. Mutje, "Estimation of the interfacial shears strength, orientation factor and mean equivalent intrinsic tensile strength in old newspaper fiber/polypropylene composites," Composites $B$, vol. 50, pp. 232-238, 2013.

[21] A. Nevarez-Rascon, A. Aguilar-Elguezabal, E. Orrantia, and M. H. Bocanegra-Bernal, "Compressive strength, hardness and fracture toughness of $\mathrm{Al}_{2} \mathrm{O}_{3}$ whiskers reinforced ZTA and ATZ nanocomposites: weibull analysis," International Journal of Refractory Metals and Hard Materials, vol. 29, no. 3, pp. 333-340, 2011.

[22] B. Zhang, H. Fu, P. Sha et al., "Anisotropic compressive deformation behaviors of tungsten fiber reinforced $\mathrm{Zr}$-based metallic glass composites," Materials Science and Engineering A, vol. 566, pp. 16-21, 2013.

[23] J. Zhang, R. Luo, Q. Xiang, and C. Yang, "Compressive fracture behavior of 3D needle-punched carbon/carbon composites," Materials Science and Engineering A, vol. 528, no. 15, pp. 50025006, 2011.

[24] B. F. Yousif and U. Nirmal, "Wear and frictional performance of polymeric composites aged in various solutions," Wear, vol. 272, no. 1, pp. 97-104, 2011.

[25] Z. Rasheva, G. Zhang, and T. Burkhart, "A correlation between the tribological and mechanical properties of short carbon fibers reinforced PEEK materials with different fiber orientations," Tribology International, vol. 43, no. 8, pp. 1430-1437, 2010.

[26] P. S. Babu, B. Basu, and G. Sundararajan, "The influence of erodent hardness on the erosion behavior of detonation sprayed WC-12Co coatings," Wear, vol. 270, no. 11-12, pp. 903-913, 2011.

[27] B. F. Yousif, A. Shalwan, C. W. Chin, and K. C. Ming, "Flexural properties of treated and untreated kenaf/epoxy composites," Materials \& Design, vol. 40, pp. 378-385, 2012. 

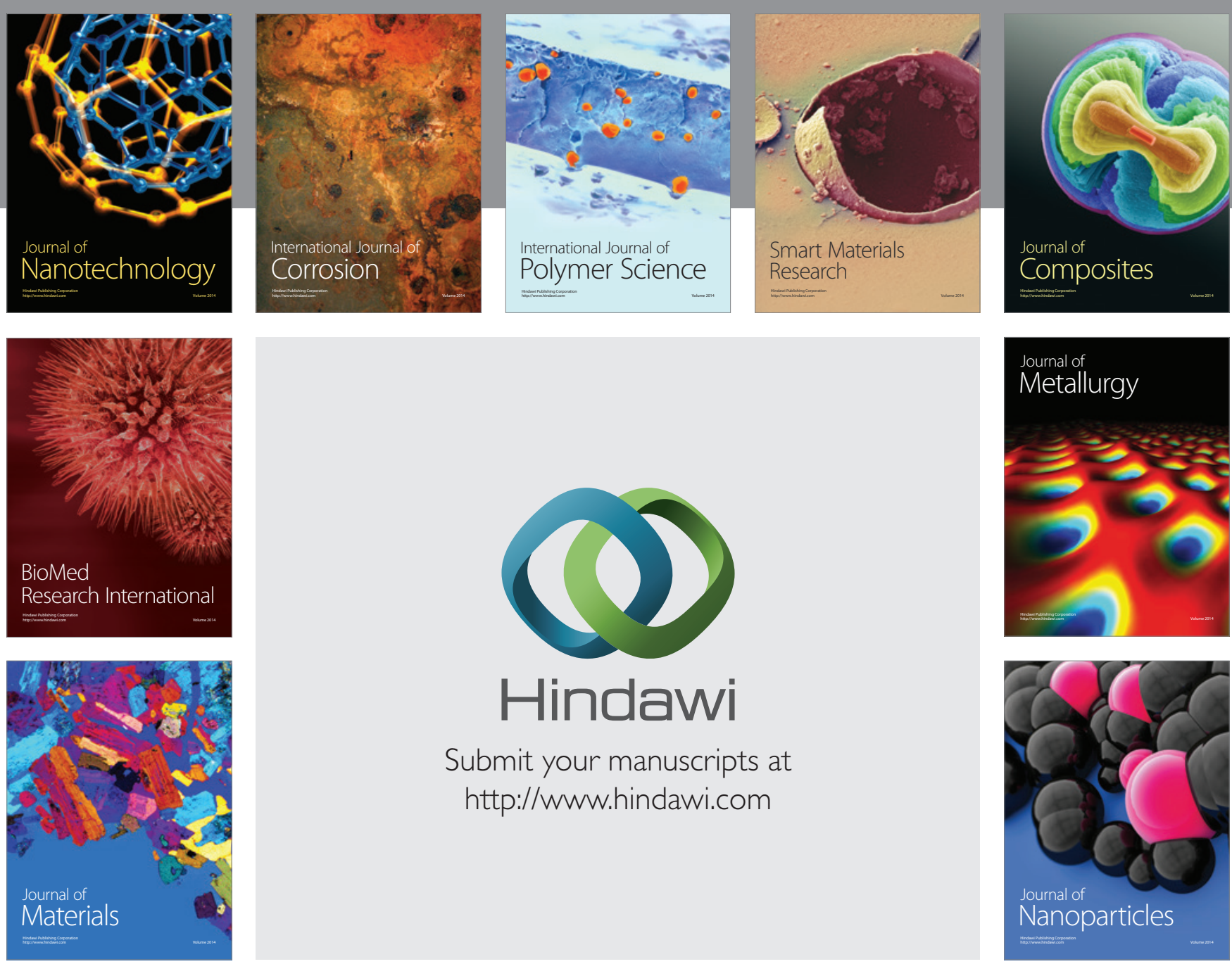

Submit your manuscripts at http://www.hindawi.com
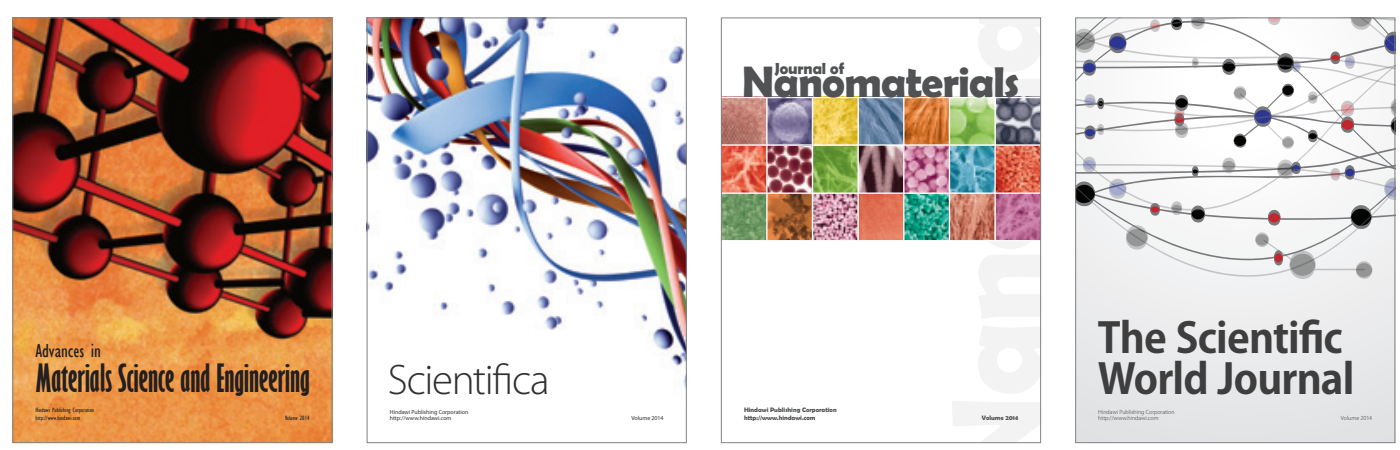

\section{The Scientific World Journal}
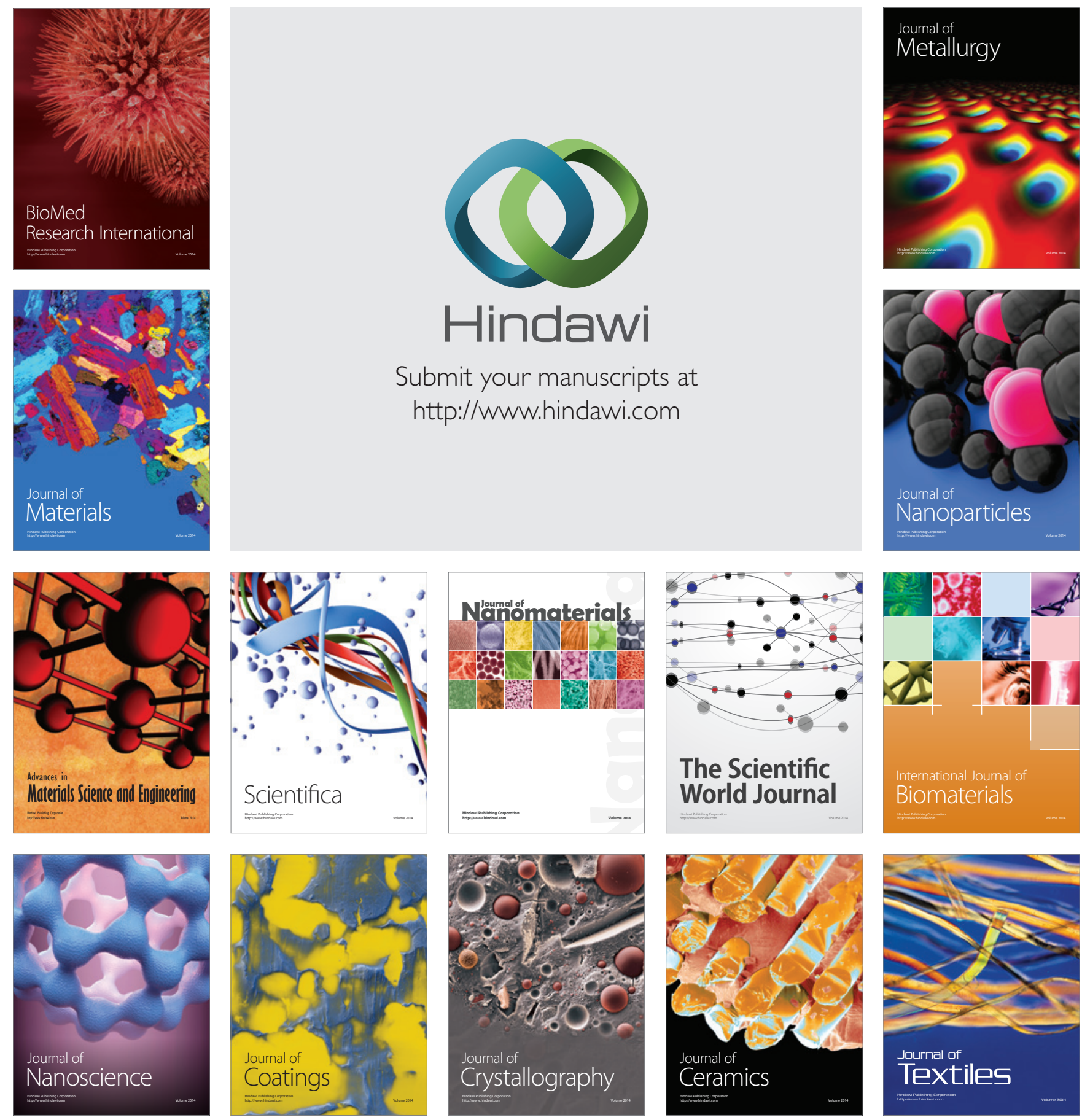